\title{
Microstructure Fabricated by Monocrystalline Silicon Anisotropic Etching in Sodium Carbonate and Sodium Bicarbonate Solutions
}

\author{
Jun-Jun Ma ${ }^{1, a}$, Rui-Zhi Luo ${ }^{2, b}$, Ya-Qin Wang $\quad{ }^{3, c}$ and Shi-Qing Man ${ }^{4, d *}$ \\ 1, 2, 3,4 School of Physics and Electronic Information Technology, Yunnan Normal University, \\ Kunming, Yunnan, China \\ a2754127618@qq.com, b1401820876@qq.com , c1045389154@qq.com, \\ dman_shiqing@yahoo.com
}

\begin{abstract}
Keywords: Microstructure; Monocrystalline silicon; Texturization; Coverage rate
Abstract. The fabrication method of microstructure for monocrystalline silicon wafers based on a mixture of sodium carbonate and sodium bicarbonate solutions under different conditions has been studied in this work. The texturization process has been evaluated in terms of the surface morphology size and the coverage rate. The experiments show that the influence of $\mathrm{Na}_{2} \mathrm{CO}_{3}$ concentration is significant by varying the concentration between $5 \mathrm{wt} \%$ and $30 \mathrm{wt} \%$. It was shown that with the concentration of $\mathrm{Na}_{2} \mathrm{CO}_{3}$ changing, the average size of pyramidal varies from $1.20 \mu \mathrm{m}$ to $2.44 \mu \mathrm{m}$. In a word, the surface were not uniform and exhibited wide bright zones in which the texturization process was not successful. However, we find it possible to get a better pyramid structure by the addition of $\mathrm{NaHCO}_{3}$. Uniform microstructure in the wafers of monocrystalline silicon were formed with $20 \mathrm{wt} \%$ sodium carbonate and $5 \mathrm{wt} \%$ sodium bicarbonate at $90{ }^{\circ} \mathrm{C}$ for $20 \mathrm{~min}$. Under optimized conditions, the textured silicon wafers surface exhibit a lower average size (about $0.96 \mu \mathrm{m}$ ) and the coverage rate is high.
\end{abstract}

\section{Introduction}

Anisotropic etching of monocrystalline silicon crystals has been known for years and it is often used in the processing of silicon devices and microstructures. In traditional technological application, the microstructure usually applied on the solar cells to reducing optical losses ${ }^{[1]}$. Because metallic substrates display unique surface plasmon properties, so they have attached enough scientific interest and great technological importance. In modern time, metallic microstructure has been widely used on the micromachining such as nanophotonic devices, data storage and biosensor ${ }^{[2]}$. Recently, the silicon nanofabrication of monocrystalline silicon has been applied in the nanoscale waveguide device ${ }^{[3]}$. When the size has reached nanometer, it also can be used on technological field. In order to control the shape of microstructure in wet etching, it is necessary to meticulously design the etching parameters such as the concentration of solutions, the temperature and the time.

Pyramid formation the surface of $\left\{\begin{array}{lll}1 & 0 & 0\end{array}\right\}$ monocrystalline silicon wafers with anisotropic texturing solutions is an important and effective measure to reduce reflection losses from the surface of silicon. The most important feature of the anisotropic behaviour of alkaline etchant is the very low etch rate of $\left\{\begin{array}{lll}1 & 1 & 1\end{array}\right\}$ surface compared to $\left\{\begin{array}{lll}1 & 0 & 0\end{array}\right\}$ or $\left\{\begin{array}{lll}1 & 1 & 0\end{array}\right\}$ surface. So the strong dependence of etch rates on crystal orientation leads to pyramid formation on $\left\{\begin{array}{lll}1 & 0 & 0\end{array}\right\}$ silicon surfaces ${ }^{[4-6]}$. Commonly, the etching solutions are different kinds of alkaline such as sodium hydroxide $(\mathrm{NaOH})$ or potassium hydroxide $(\mathrm{KOH})$ with a high concentration of isopropyl alcohol (IPA $)^{[7]}$. But IPA is an expensive chemical product and has toxicity. To eliminate these disadvantages of IPA, some researchers used other solutions. Alternative solvents are sodium carbonate $\left(\mathrm{Na}_{2} \mathrm{CO}_{3}\right)^{[8]}$, potassium carbonate $\left(\mathrm{K}_{2} \mathrm{CO}_{3}\right)^{[9]}$ and sodium phosphate $\left(\mathrm{Na}_{3} \mathrm{PO}_{4}\right)^{[10]}$. These solutions are superior to the conventional solutions in terms of cost and environmental protection, because there is no need of IPA for fabrication of microstructure. In this paper, an efficient and important preparation method of microstructure for monocrystalline silicon wafers with sodium carbonate $\left(\mathrm{Na}_{2} \mathrm{CO}_{3}\right)$ and sodium bicarbonate solutions $\left(\mathrm{NaHCO}_{3}\right)$ were studied. 


\section{Experiments}

The experiments were performed with P-type $<100>$ oriented monocrystalline silicon. The samples with the size of $20 \mathrm{~mm} \times 20 \mathrm{~mm}$ were cut from adjacent wafers ${ }^{[1-13]}$. Before etching, wafers were cleaned by the following procedures. The first step was to degrease the samples by cleaning the wafers in ethanol during five minutes. The second step was to remove damage on the surface caused by sawing ${ }^{[14]}$. This step was carried out in diluted hydrofluoric acid (4 wt\%) for $30 \mathrm{~s}$ and rinsed in deionised water. The cleaned wafers were took place in a specially designed of the sealing device inside the mixed solution for a desired time ${ }^{[15]}$. Then these samples were etching in different mass ratios of $\mathrm{Na}_{2} \mathrm{CO}_{3}$ and $\mathrm{NaHCO}_{3}$ at $90{ }^{\circ} \mathrm{C}$. The wafers were kept in each solution for different time: 5 min, $10 \mathrm{~min}, 15 \mathrm{~min}, 20 \mathrm{~min}, 25 \mathrm{~min}$ and $30 \mathrm{~min}$. After the etching process, the samples were washed into absolute ethanol solution and deionized water again, then they were dried oven for tests. The surface morphology was studied with Zeiss EVO MA10 (Carl-Zeiss, Germany) scanning electronic microscope $(\mathrm{SEM})^{[16]}$.

\section{Results and Discussion}

A. Influence of $\mathrm{Na}_{2} \mathrm{CO}_{3}$ Concentration at $90^{\circ} \mathrm{C}$.

First, we varied the $\mathrm{Na}_{2} \mathrm{CO}_{3}$ concentration from $10 \mathrm{wt} \%$ to $30 \mathrm{wt} \%$ and each group has added $\mathrm{NaHCO}_{3}$ or not. On the basis of previous studies, etching was carried out at $90{ }^{\circ} \mathrm{C}$ for $20 \mathrm{~min}$. As a result of experiments, all of the pyramid size and coverage rate are listed in Table 1.

Table 1 Comparison of the microstructure size and coverage rate with different concentration of sodium carbonate and sodium bicarbonate solutions

\begin{tabular}{cccccc}
\hline $\begin{array}{c}\mathrm{Na}_{2} \mathrm{CO}_{3} \\
{[\mathrm{wt} \%]}\end{array}$ & $\begin{array}{c}\mathrm{NaHCO}_{3} \\
{[\mathrm{wt} \%]}\end{array}$ & $\begin{array}{c}\text { Maximum Size } \\
{[\mu \mathrm{m}]}\end{array}$ & $\begin{array}{c}\text { Minimun Size } \\
{[\mu \mathrm{m}]}\end{array}$ & $\begin{array}{c}\text { Average Size } \\
{[\mu \mathrm{m}]}\end{array}$ & $\begin{array}{c}\text { Coverage Rate } \\
10\end{array}$ \\
\hline 5 & 0 & 3.22 & 1.45 & 2.10 & Low \\
15 & 0 & 4.35 & 0.94 & 2.44 & Regular \\
20 & 0 & 3.19 & 1.32 & 2.02 & Regular \\
25 & 0 & 2.33 & 0.75 & 1.20 & Low \\
30 & 0 & 3.24 & 0.92 & 1.46 & Regular \\
5 & 5 & 4.12 & 1.58 & 2.24 & Regular \\
10 & 5 & 3.33 & 1.56 & 2.50 & Low \\
15 & 5 & 2.72 & 1.03 & 2.22 & Low \\
20 & 5 & 1.80 & 1.27 & 1.72 & Regular \\
25 & 5 & 1.93 & 0.26 & 0.96 & High \\
30 & 5 & 3.12 & 0.96 & 1.29 & Regular \\
\hline
\end{tabular}

From the table, it can be seen that the size of the biggest microstructure is $4.35 \mu \mathrm{m}$ and the smallest microstructure is $0.26 \mu \mathrm{m}$, average size varies from $0.96 \mu \mathrm{m}$ to $2.50 \mu \mathrm{m}$. In the case of using single reagent of $\mathrm{Na}_{2} \mathrm{CO}_{3}$, the concentration becomes higher, the average size becomes smaller, but when the concentration over $20 \%$, the size becomes larger gradually. The minimum average size is $1.20 \mu \mathrm{m}$. When $\mathrm{NaHCO}_{3}$ was added, the minimum average size is $0.96 \mu \mathrm{m}$. In addition, the coverage rate is high. All these mean that this kind of etchant can successfully get microstructure.

Fig. 1 is the SEM images of pyramid structure when we use the single reagent of $\mathrm{Na}_{2} \mathrm{CO}_{3}$. The SEM picture showed that at 5\% concentration, the sample surface was not fully etched. As the concentration of $\mathrm{Na}_{2} \mathrm{CO}_{3}$ was increased, so too did the number and size of larger pyramidal structures. Although the microstructure is excellent and the uniformity is high when the concentration reaches $20 \%$, the sample surface is not completely covered. SEM images of the $\mathrm{NaHCO}_{3}$ addition are shown in Fig. 2. It is found that the coverage rate is increased by the addition of $\mathrm{NaHCO}_{3}$. When we add 5 $\mathrm{wt} \% \mathrm{NaHCO}_{3}$ to $20 \mathrm{wt} \% \mathrm{Na}_{2} \mathrm{CO}_{3}$ solutions, we obtain an excellent microstructure. 

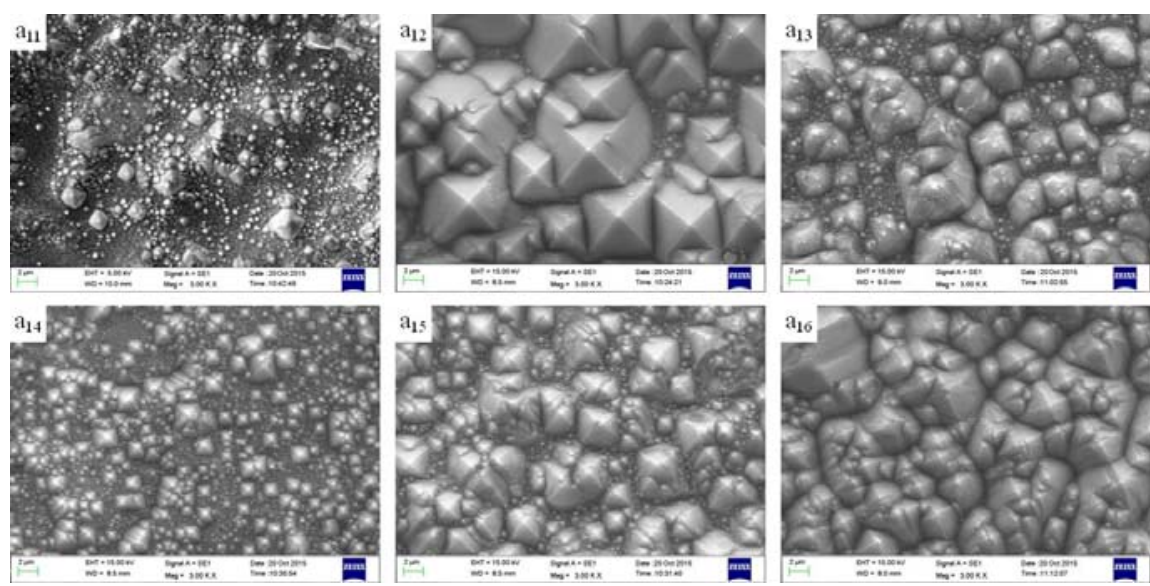

Fig. 1 Scanning Electronic Microscope (SEM) images of monocrystalline silicon wafers microstructure textured without $\mathrm{NaHCO}_{3}$ and with different concentration of $\mathrm{Na}_{2} \mathrm{CO}_{3}: \mathrm{a}_{11}(5 \mathrm{wt} \%), \mathrm{a}_{12}(10 \mathrm{wt} \%), \mathrm{a}_{13}(15 \mathrm{wt} \%), \mathrm{a}_{14}(20 \mathrm{wt} \%)$,

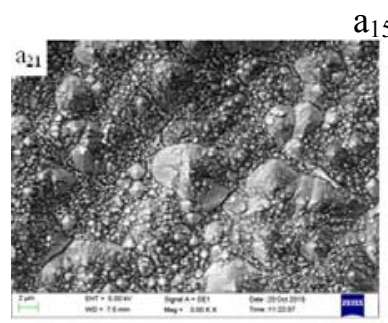
$a_{15}(25 w t \%), a_{16}(30 w t \%)$.
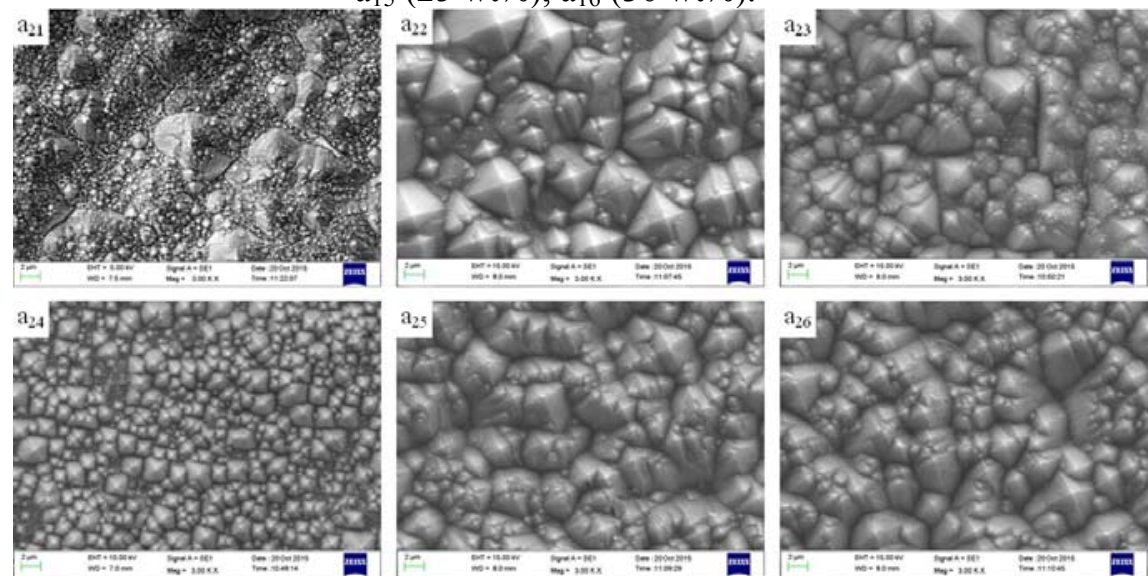

Fig. 2 Scanning Electronic Microscope (SEM) images of monocrystalline silicon wafers microstructure textured with $5 \mathrm{wt} \% \mathrm{NaHCO}_{3}$ and with different concentration of $\mathrm{Na}_{2} \mathrm{CO}_{3}$ : $a_{24}(20 w t \%), a_{25}(25 w t \%), a_{26}(30 w t \%)$.

Fig. 3 is the SEM image of samples at $45^{\circ}$ incidence angle. The photograph shows that a number of pits were formed on surface of samples, which were not only the morphology size is smaller, but also the uniformity is higher. The distribution of pyramid average sizes under the optimum process condition is schematically shown in Fig. 4. It is found that most diameter sizes are centered in $0.9 \mu \mathrm{m}$, which account for $58 \%$. The number of too big pyramids are few, so too small pyramids are the same.

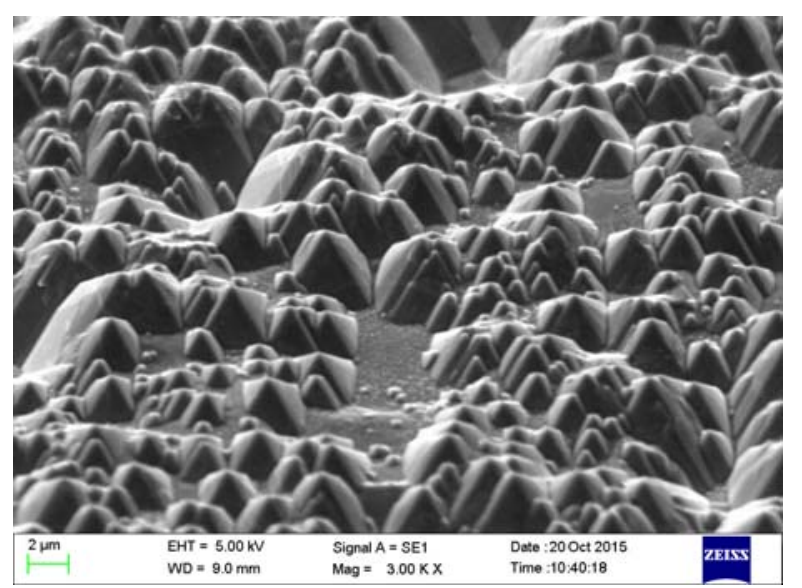

Fig. 3 Scanning Electronic Microscope (SEM) image at $45^{\circ}$ incidence angle of monocrystalline silicon wafers microstructure textured according to the optimum conditions: $20 \mathrm{wt} \% \mathrm{Na}_{2} \mathrm{CO}_{3}$ and $\quad 5 \mathrm{wt} \% \mathrm{NaHCO}_{3}$ solutions for 20 min at $90^{\circ} \mathrm{C}$. 


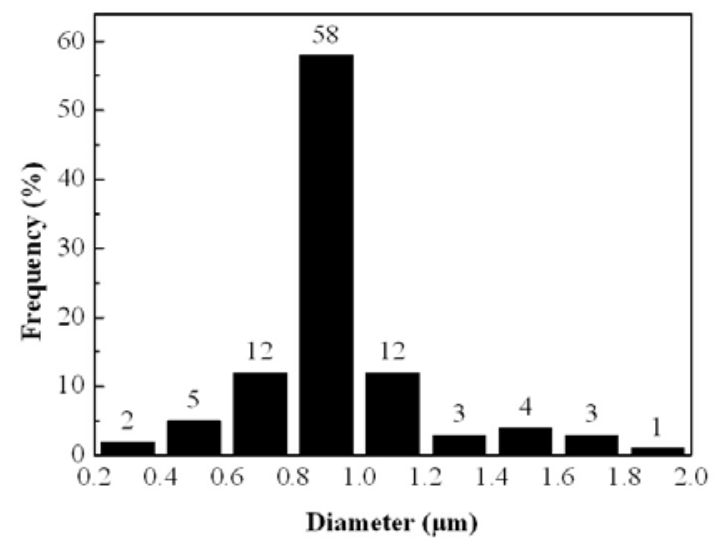

Fig. 4 Distribution of pyramid sizes of sample prepared with the optimum conditions: $20 \mathrm{wt} \% \mathrm{Na}_{2} \mathrm{CO}_{3}$ and 5 $\mathrm{wt} \% \mathrm{NaHCO}_{3}$ solutions for $20 \mathrm{~min}$ at $90{ }^{\circ} \mathrm{C}$.

B. Influence of Etching Time at $90^{\circ} \mathrm{C}$.

Next, an analysis of etching time of the solutions consisting of $20 \mathrm{wt} \% \mathrm{Na}_{2} \mathrm{CO}_{3}$ and $5 \mathrm{wt} \%$ $\mathrm{NaHCO}_{3}$ at $90{ }^{\circ} \mathrm{C}$ was carried out by varying the time from $5 \mathrm{~min}$ to $30 \mathrm{~min}$. An optimum treatment time of 20 min was determined. Table 2 summarizes the size and the coverage rate of microstructure.

\begin{tabular}{ccccc}
\multicolumn{6}{c}{ Table 2 Comparison of the microstructure size and coverage rate with different etching time } \\
$\begin{array}{r}\begin{array}{r}\text { Time } \\
{[\mathrm{min}]}\end{array} \\
\text { Maximum Size } \\
{[\mu \mathrm{m}]}\end{array}$ & $\begin{array}{c}\text { Minimum Size } \\
{[\mu \mathrm{m}]}\end{array}$ & $\begin{array}{c}\text { Average Size } \\
{[\mu \mathrm{m}]}\end{array}$ & Coverage Rate \\
\hline 5 & 3.13 & 1.05 & 1.78 & Low \\
10 & 3.14 & 1.02 & 1.82 & Regular \\
15 & 1.79 & 0.61 & 1.06 & Low \\
20 & 1.84 & 0.24 & 0.94 & High \\
25 & 1.82 & 0.66 & 1.08 & Regular \\
30 & 2.94 & 0.96 & 1.76 & High \\
\hline
\end{tabular}

From the table, it is noticed that there is remarkably different size and coverage rate with different etching time. Among them, the biggest microstructure is $3.14 \mu \mathrm{m}$ and the smallest microstructure is $0.24 \mu \mathrm{m}$, average size varies from $0.94 \mu \mathrm{m}$ to $1.82 \mu \mathrm{m}$. In total, the coverage rate is regular.

The SEM images of pyramids structure surface with different etching time are shown in Fig. 5. It can be stated that the increase in etching time resulted in the reduction of the pyramid size. Moreover, the uniformity and coverage rate have been improved. Fig. 6 is the SEM image of etched samples at $45^{\circ}$ incidence angle under the optimum parameters. That is the concentration of $\mathrm{Na}_{2} \mathrm{CO}_{3}$ is $20 \mathrm{wt} \%$, the concentration of $\mathrm{NaHCO}_{3}$ is $5 \mathrm{wt} \%$, the temperature is $90{ }^{\circ} \mathrm{C}$ and the etching time is $20 \mathrm{~min}$. Under these conditions, good surface coverage is obtained. The pyramids are uniform, which sizes are between $0.8 \mu \mathrm{m}$ and $1.0 \mu \mathrm{m}$.
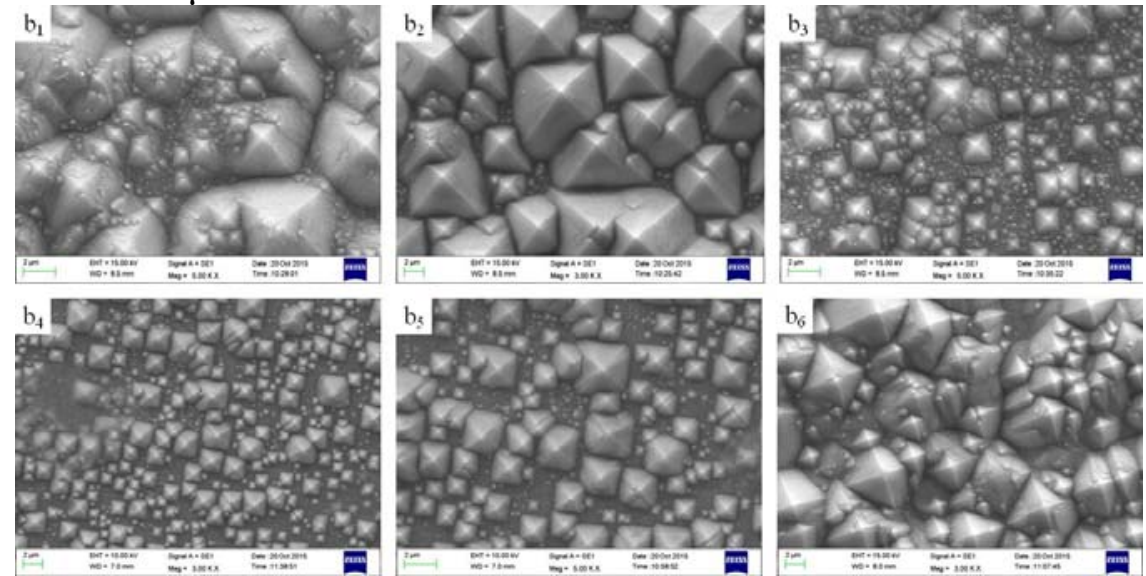

Fig. 5 Scanning Electronic Microscope (SEM) images of monocrystalline silicon wafers microstructure textured with different etching time: $b_{1}(5 \mathrm{~min}), b_{2}(10 \mathrm{~min}), b_{3}(15 \mathrm{~min}), \mathrm{b}_{4}(20 \mathrm{~min}), \mathrm{b}_{5}(25 \mathrm{~min}), \mathrm{b}_{6}(30 \mathrm{~min})$. 


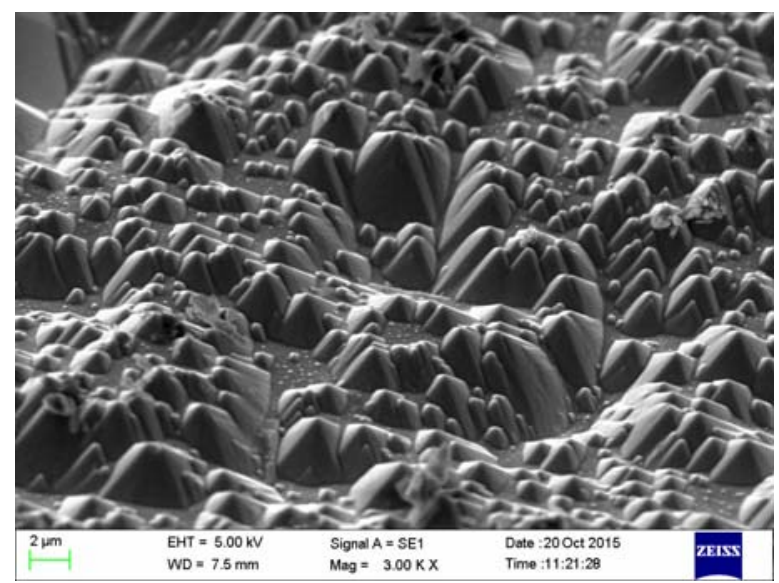

Fig. 6 Scanning Electronic Microscope (SEM) image at $45^{\circ}$ incidence angle of monocrystalline silicon wafers microstructure textured under the optimum parameters: $20 \mathrm{wt} \% \mathrm{Na}_{2} \mathrm{CO}_{3}$ and $5 \mathrm{wt} \% \mathrm{NaHCO}_{3}$ solutions for $20 \mathrm{~min}$ at $90{ }^{\circ} \mathrm{C}$.

Comparison of the average size of microstructure and the etching time are shown in Fig. 7. The image clearly show that the etching time is an important factor for the fabrication of morphology. In other words, the average size of microstructure decreases as the etching time increases. The optimum etching time is $20 \mathrm{~min}$. When the etching time was more than $20 \mathrm{~min}$, the average size of microstructure began to larger. Fig. 8 shows the distribution of pyramid average sizes under the optimum process conditions. It can be clearly seen that most diameter sizes of microstructure are between $0.8 \mu \mathrm{m}$ and $1.0 \mu \mathrm{m}$, which account for $62 \%$. Besides, the percentage of diameter sizes which below $0.6 \mu \mathrm{m}$ and above $1.4 \mu \mathrm{m}$ less than $20 \%$ in total. All these data indicate the pyramids are uniform and discontinuous.

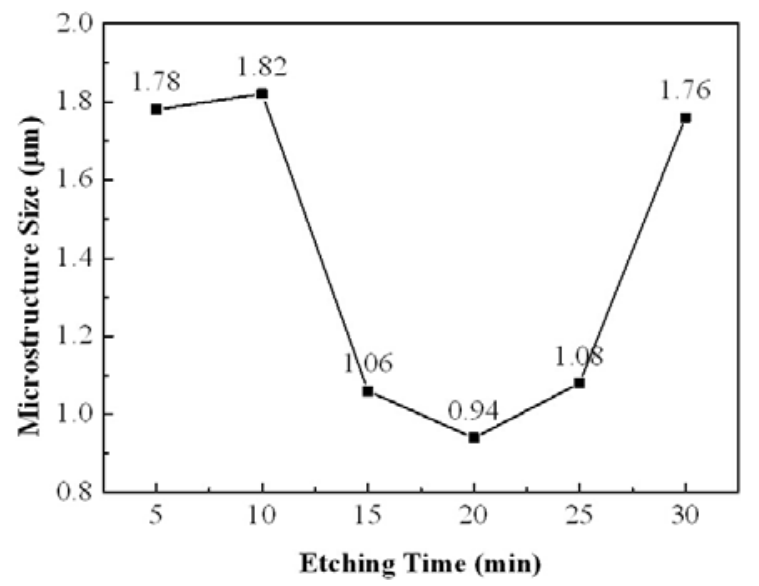

Fig. 7 The relationship between average size of microstructure and different etching time.

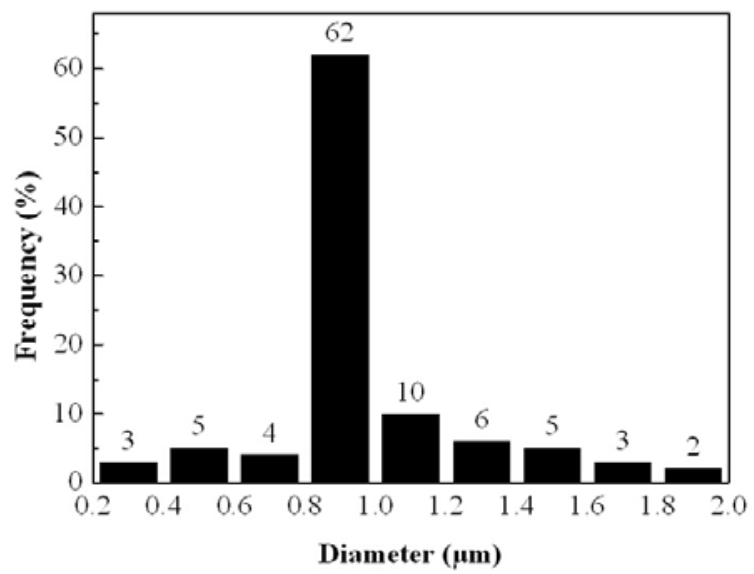

Fig. 8 Distribution of pyramid sizes of sample prepared with the optimum parameters: $20 \mathrm{wt} \% \mathrm{Na}_{2} \mathrm{CO}_{3}$ and 5 $\mathrm{wt} \% \mathrm{NaHCO}_{3}$ solutions for $20 \mathrm{~min}$ at $90{ }^{\circ} \mathrm{C}$. 


\section{Conclusions}

In this paper, the microstructure of monocrystalline silicon wafers using sodium carbonate and sodium bicarbonate solutions have been investigated. Furthermore, we studied the size and coverage rate of pyramid under different experimental conditions. It is shown that the solution concentration and the etching time determine the texture of the silicon surface. From the result of experiments, we found texturing is accelerated and the size of morphology becomes smaller by the addition of $\mathrm{NaHCO}_{3}$ without changing the etching parameters. The results indicate that $\mathrm{CO}_{3}{ }^{-}$seems to act the initiator of microstructure and the $\mathrm{HCO}_{3}{ }^{-}$seems to play the same role as IPA. Meanwhile, to obtain the dense and uniformly distributed pyramid structures from the SEM images, the optimized condition is $20 \mathrm{wt} \% \mathrm{Na}_{2} \mathrm{CO}_{3}, 5 \mathrm{wt} \% \mathrm{NaHCO}_{3}, 90{ }^{\circ} \mathrm{C}$ and $20 \mathrm{~min}$. Under these conditions, the average size of diameter is $0.96 \mu \mathrm{m}$. This approach is promising can be applied for the large-scale industrial production of monocrystalline silicon solar cells with relatively lower cost.

\section{Acknowledgements}

This work was supported by the National Natural Science Foundation of China (NSFC) (Grant No. 21171072 and Grant No. 21361028).

\section{References}

[1] T. Koschwitz, B. Meinel and J. Acker: Energy Procedia, Vol. 38 (2013), p. 234-242.

[2] J. X. Fang, S. Y. Du and etal: Nano Letters, Vol. 10 (2010), p. 5006-5013.

[3] Y. Jia, J. Q. Wei and etal: Advanced Materials, Vol. 20 (2008), p. 4594-4598.

[4] I. Zubel, F. Granek and etal: Applied Surface Science, Vol. 258 (2012), p. 9067-9072.

[5] F. Watanabe, S. Kodambaka and etal: Surface Science, Vol. 572 (2004), p. 425-432.

[6] J. Zhao, A. Wang and etal: Applied Physics Letters, Vol. 73 (1998), p. 1991-1993.

[7] Z. Xi, D. Yang and etal: Renewable Energy, Vol. 29 (2004), p. 2101-2107.

[8] Y. Nishimoto and K. Namba: Solar Energy Materials and Solar Cells, Vol. 61 (2000), p. 393-402.

[9] R. Chaui, M. Lachab and etal, Proceedings of 14th European Photovoltaic Solar Energy Conference, Barcelona, 1997, p. 812.

[10] Z. Q. Xi, D. R. Yang and D. L. Que: Solar Energy Materials and Solar Cells, Vol. 77 (2003), p. 255-263.

[11] C. Y. Zhao, H. Y. Zhang and Y. Wang: Advanced Materials Research, Vol. 628 (2013), p. 211-216.

[12] D. W. Branch, B. C. Wheeler and etal: IEEE Transactions on Bio-medical Engineering, Vol. 47 (2000), p. 290-300.

[13] K. Biswas, and S. Kal: Microelectronics Journal, Vol. 37 (2006), p. 519-525.

[14] P. A. Deymier, J. O. Vasseu and etal: Journal of Applied Physics, Vol. 90 (2001), p. 4211-4218.

[15] J. Yoo, J. Cho and etal: Journal of the Korean Physical Society, Vol. 60 (2012), p. 2071-2074.

[16] J. Dian, A. Macek and etal: Applied Surface Science, Vol. 238 (2004), p.169-174. 